\title{
Co-Mutagenic Activity of Phenoxyherbicides MCPA- and MCPB-Ethylester in the Ames Assay
}

\author{
Norio Shibuya, Tatsuo Ohta, ${ }^{*}$ Hiroshi Sakai, $†$ Shuko \\ Takagi, $\ddagger$ Junko Magara $\ddagger$ and Masaharu Yamamoto $\ddagger$ \\ Chemical Laboratory, Niigata Academy of Medical \\ Technology, Nïgata 950-21, *Department of Biology, \\ Niigata College of Pharmacy, Niigata 950-21, †Niigata \\ Prefectural Research Laboratory for Health and \\ Environment, Niigata 950-21, and $\ddagger$ Department of \\ Hygiene and Preventive Medicine, Nïgata University School \\ of Medicine, Niigata 951
}

Shibuya, N., Ohta, T., Sakai, H., Takagi, S., Magara, J. and Yamamoto, M. Co-Mutagenic Activity of Phenoxyherbicides MCPA- and MCPB-Ethylester in the Ames Assay. Tohoku J. Exp. Med., 1990, 160 (2), 167-168_ Mutagenicity and co-mutagenicity of MCPA- and MCPB-ethylester were examined in the Ames assay. It was found that they enhance the mutagenic action of 2-aminoanthracene in the Ames assay, although they were not mutagenic. - phenoxyherbicides; MCPA- and MCPB-ethylester; Ames assay

In spite of the extensive use of the phenoxyherbicides, 4-chloro-2-methylphenoxyacetic acid ethylester (MCPA-E) and 4-chloro-2-methylphenoxybutyric acid ethylester (MCPB-E), in the paddy field in Japan, little has been known about the long-term effects of these compounds from the point of view of mutagenicity and carcinogenicity in humans. In order to know the genetic effects of these compounds, we have already tested the action of MCPA-E in the rec assay and found that it is co-mutagenic, i.e., it amplified the growth inhibition originally induced by mitomycin $\mathrm{C}$ in the rec assay (Yamamoto et al. 1988). In the present study, we further investigated its co-mutagenicity using Ames assay. In addition we investigated the co-mutagenicity of structurally similar chemical, MCPB-E, in the same test system.

MCPA-E and MCPB-E were extracted with dichloromethane from the commercial products, perchased from Nissan Chemical Industry, Ltd.(Tokyo). Purities of MCPA-E and MCPB-E were about $96 \%$ and $98 \%$, respectively, based on electron capture detector gas chromatography. These chemicals were dissolved in dimethyl sulfoxide.

The Ames assay was done according to a preincubation method described by Yahagi et al. (1977) using Salmonella typhimurium strain TA100 and TA98 with or without S9 mix. The testing was made with duplicate plates, and MCPA-E and MCPB-E were tested in seven doses without toxic effect. The dose ranges of MCPA-E and MCPB-E were 2.89-185 and 4.06-260 in $\mu \mathrm{g} /$ plate in the system with $\mathrm{S} 9 \mathrm{mix}, 0.0452-2.89$ and 0.0317-2.03 $\mu \mathrm{g}$ plate in the system without S9 mix, respectively. Mutagenicity of $2 \mu \mathrm{g} / 2$-aminoanthracene (2-AA) per plate was determined in the presence of MCPA-E or MCPB-E at the varrious doses with S9

Received November 9, 1989 ; revision accepted for publication January 10, 1990. 

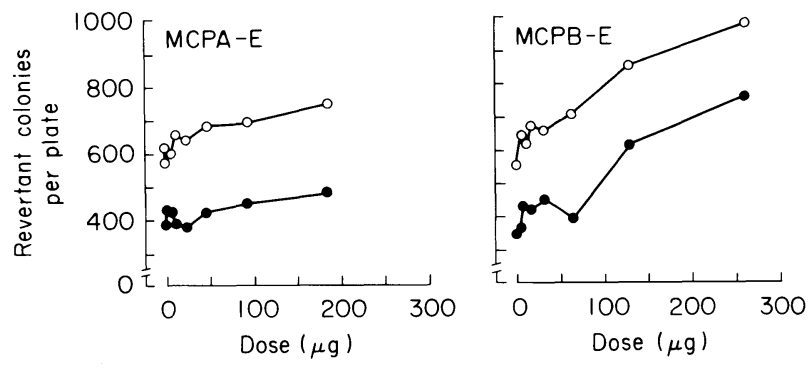

Fig. 1. Effects of MCPA-E and MCPB-E on mutagenicity of 2-aminoanthracene (2-AA) by Ames assay with S9. Every plate except negative control was dosed with $2 \mu \mathrm{g}$ of 2-AA as promutagen. Spontaneous revertants, 88-122 for TA100 (-०-) and 24-35 for TA98 (--), were subtracted.

mix to estimate effects of the testing materials on the mutagenic expression of the promutagen 2-AA.

No mutagenicity of the test materials was observed in the test system. The mutagenicity of 2-AA clearly increased with an elevation of dosage of MCPB-E and slightly increased with MCPA-E (Fig. 1). It can be inferred that these chemicals or contaminants may exhibit a DNA-modifying activity under the influence of mutagen 2-AA, or may react with 2-A A in the presence of $\mathrm{S} 9 \mathrm{mix}$ to give more active ultimate mutagen than in the case of 2-A A alone, or may elevate the activity of $\mathrm{S} 9 \mathrm{mix}$ to transform into an ultimate mutagen. Further study should be directed to the investigation of the present inference.

\section{References}

1) Yahagi, T., Nagao, M., Seino, Y., Matsushima, T., Sugimura, T. \& Okada, M. (1977) Mutagenicities of N-nitorosamines on Salmonella. Mutat. Res., 48, 121-130.

2) Yamamoto, M., Magara, J., Takagi, S., Shibuya, N., Chen, W. \& Endoh, K. (1988) Activity of agricultural chemicals to modify mitomycin $\mathrm{C}$ induced growth inhibition of Bacillus subtilis in rec assay. Tohoku J. Exp. Med., 155, 385-386. 